\title{
Effect of particles on hydrodynamics and mass transfer in a slurry bubble column: Correlation of experimental data
}

\author{
Huahai Zhang ${ }^{1}$, Zhongshan Guo ${ }^{1}$, Yuelin Wang ${ }^{1}$, Xiankun Shen ${ }^{1}$, and Tiefeng Wang ${ }^{1}$ \\ ${ }^{1}$ Tsinghua University
}

December 30, 2021

\begin{abstract}
The effects of particle concentration and size on hydrodynamics and mass transport in a slurry bubble column were experimentally studied. With increasing particle concentration, the averaged gas holdup, gas holdup of small bubbles and gas-liquid volumetric mass transfer coefficient decreased, while the gas holdup of large bubbles increased slightly. With increasing particle size, the averaged gas holdup and kla remained unchanged when the particle size increased from 55 to 92 ?m, but decreased significantly when the particle size was further increased to 206 ?m. A liquid turbulence attenuation model which could quantitatively describe the effects of particle concentration and size was first proposed. Semi-empirical correlations were obtained based on extensive experimental data in a wide range of operating conditions and corrected liquid properties. The gas holdup and mass transfer coefficient calculated by the correlations agreed with the experimental data from both two-phase and three-phase bubble columns
\end{abstract}

\section{Hosted file}

Manuscript_Exp-particle_20211218.pdf available at https://authorea.com/users/404261/articles/ 551076-effect-of-particles-on-hydrodynamics-and-mass-transfer-in-a-slurry-bubble-columncorrelation-of-experimental-data 